\title{
VIDA Y OBRA DE UN VANGUARDISTA OLVIDADO: LUIS MOSQUERA (1890-1955)
}

\author{
José María Barrera López
}

La historia de la vanguardia hispánica está edificada sobre un mundo de sombras. Marginaciones voluntarias, olvidos malintencionados, recuperaciones forzosas y parcelaciones interesadas, nos han llevado continuamente a replantearnos la parcialidad de su construcción y a cuestionarnos su validez. Máxime cuando, todavía hoy, se minusvaloran los verdaderos focos de su irrupción o se tildan de «menores» o «marginales» a escritores de los que se desconoce una gran parte de su obra. La marginación puede, en literatura, convertirse en un tópico más.

En lo que concierne a nuestro ámbito, ya en 1959, Juan Collantes de Terán señalaba que «el atlas literario de los istmos en la Península tuvo a partir de 1919 un punto geográfico importante: Sevilla. En la capital andaluza, y desde la revista Grecia se enarboló la bandera del Ultraísmo. (...) Grecia cumplió su cometido y alcanzó los objetivos que se proponía luchando contra él ya adocenado modernismo y rompiendo lanzas a favor de una literatura de vanguardia» ${ }^{1}$. Y, un poco antes, en 1955, Joaquín Romero Murube reclamaba el hacer «la historia literaria de Sevilla en estos cincuentas años» y a propósito de Grecia y Mediodía, llamaba la atención sobre «figuras aisladas o periféricas en orden a las órbitas» de estas publicaciones (Izquierdo, Romero Martínez...) y aquellas otras «que oscilaron entre ambas publicaciones» ${ }^{2}$.

A pesar de estos tempranos testimonios, y aunque ya comienzan a ser estudiosos autores significativos del Vltra de Sevilla (Isaac del Vando, José María Ro-

1 Juan Collantes de Terán: «Dos poetas de Sevilla en el Creacionismo de Vicente Huidobro» Estudios Americanos. Revista de Síntesis e Interpretación. Vol. XVIII, núms. 96-97, sep-oct, 1959, p. 175.

2 J. Romero Murube: «Temas Literarios. Ha muerto un escritor sevillano» El Correo de Andalucía, Sevilla, año LVII, n. 18.424, 27 de noviembre de 1955, p. 2. 
mero, Pedro Garfias ${ }^{3}$ ), una gran mayoría de ellos (Pedro Raida, Luis Claudio Mariani, Manuel Calvo, González Olmedilla...) quedan aún pendientes de un análisis más detallado ${ }^{4}$. Con frecuencia se repiten las mismas ideas de Méndez Bejarano o Cuenca Benet ${ }^{5}$ que imposibilitan una verdadera valoración de su obra. Incluso dentro del Vltra, algunos aspectos como el teatro o la novela han sido sistemáticamente desestimados por la crítica y son totalmente inéditos ${ }^{6}$.

De toda la nómina de la vanguardia sevillana es de destacar el «modesto y buen escritor» - según Romero Murube- que fue Luis Mosquera, totalmente hoy olvidado. Autor citado por Gloria Videla en su monografía sobre El Ultraís$m o$, junto con 16 compañeros «que estuvieron también relacionados con Ultra» ${ }^{7}$, recordando con otros «en una posición secundarias, de meros domésticos del grupo» ${ }^{8}$ o incluido en el grupo «de otros, de los que apenas queda el recuerdo en las páginas de los diarios y revistas de la época como entusiastas defensores de los postulados ultraístas» ${ }^{9}$.

Guillermo de Torre, en la clasificación temprana que hizo de los ultraístas en su manual Literaturas europeas de vanguardia, lo incluyó en el grupo tercero, como «indeciso», frente a los «verdaderos» y los «colaboradores«. Mosquera quedaba unido a Rogelio Buendía, E. López Parra, Heliodoro Puche, Ramón Prieto y Romero y Ángel Dotor: «Estos, con el jovial malabarista Francisco Vighi, no han dejado de asimilarse en ocasiones la intención ultraísta» ${ }^{10}$. Otro ultraísta, compañero en el Vltra de Sevilla, Pedro Garfias, desde las páginas de Cervantes, en marzo de 1919, contestaba a los ataques de D. Germán Gómez de la Mata en La Jornada con un fragmentos de «Ensayo de Moderna Lírica» (publicado en Grecia, n. 11. 15 marzo 1919, p. 11) de Luis Mosquera, para que aquel comprendiese que «no sólo el verso libre y la onomatopeya son las características del ultraísmo» ${ }^{11}$. El autor de El Ala del Sur. Poemas (1926) en su artículo colofón de

3 Miguel Cruz: Vida y obra de Isaac del Vando-Villar. Libro en preparación, 1988; Eloy Navarro Domínguez-Adame: La Obra literaria de José M. ${ }^{a}$ Romero. Tesis de Licenciatura, junio 1986. José M. Barrera López: Proceso Textual de la obra poética completa de P. Garfias. Tesis doctoral.

4 Noticias biobibliográficas de estos autores y sus colaboraciones completas en la prensa y revistas sevillanas en José María Barrera López: El Ultraísmo de Sevilla (Historia y Textos) Sevilla, Ed. Alfar, col. Alfar/Universidad, n. 29, 1987, 2 vols.

5 Mario Méndez Bejarano: Diccionario de escritores, maestros y oradores naturales de Sevilla y su actual provincia. 3 vols., Sevilla, 1922-1925; Cuenca Benet: Biblioteca de Autores Andaluces. Modernos y Contemporáneos. 2 vols., La Habana, 1921-1925.

6 P. Raida escribió Regeneración, Novio de Sevilla, Manuel Calvo Ochoa, La cita, Las dos Patrias, P. Garfias y P. Iglesias, Los hijos de la luna, etc.

7 Gloria Videla: El Ultraísmo. Estudios sobre movimientos poéticos de vanguardia en España. B.R.H. Ed. Gredos, 2a ed., 1971, p. 166.

8 J. de Dios Ruiz - Copete: Panorama poético de Sevilla (de las brumas del Medievo a las postrimerías el S. XX). Ed. Barro, col. Vasija, n. 20, Sevilla, 1983, p. 22.

9 José Luis Roca: «Noticia sobre la revista ovetense» 'Vltra'» Homenaje a Álvaro Galmés de Fuentes, T. II (Universidad de Oviedo, Madrid, Ed. Gredos, 1985), p. 428.

10 Guillermo de Torre: Literaturas europeas de vanguardia. Madrid, Rafael Caro Raggio Ed., 1925 , p. 79.

11 Pedro Garfias: «Anales literarios. El ’Ultra'» Cervantes, Madrid, año IV, marzo 1919. 
la serie «Del Ultraismo», publicada en El Heraldo de Madrid, añade el nombre de Mosquera al de Tomás Luque, Rogelio Buendía, Jaime Ibarra y Lucía SánchezSaornil, «otros nombres de obra muy estimable que habría que añadir a la lista (del Ultra) $\gg{ }^{12}$. Sin embargo, desde muy pronto, tuvo que soportar la ridiculización de su obra — como le sucedió al mismo Garfias-y someterse a las críticas de los académicos. Así, Luis Astrana Marín, a propósito del poema cubista «Viaje orbicular» escribió: «He aquí una de las características poesías el Ultra. Fírmala un Mosquera. Léanla — si pueden - y no se amosquen:

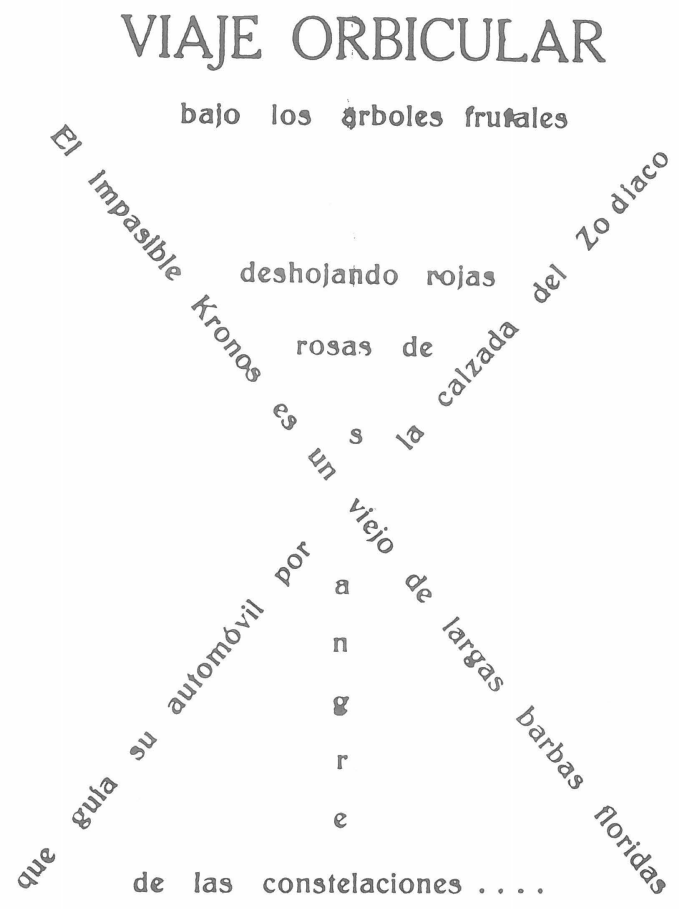

¿Qué les parece a ustedes? Muy bonito ¿eh? Tomamos la anterior composición... tipográfica de la revista Grecia, albañal de todos los atrevimientos líricos (...). Así, la escuela ha hecho innumerables prosélitos entre la juventud o lactancia literaria, por aquello de que todo se pega menos la hermosura» ${ }^{13}$. La crítica y el desconocimiento de su producción han llegado hasta nuestros días. Germán Gullón en su Poesía de la Vanguardia no lo recoge, aunque sí da cabida a Pedro

12 Pedro Garfias: «Después de unos artículos. Omisiones» El Heraldo de Madrid, 19 de julio 1934, en José María Barrera López El Ultraísmo... cit. T. II, p. 241.

13 Luis Astrana Marín: Gente, gentecilla y gentuza. Críticas y sátiras. Ed. Reus, Biblioteca Bergamín, s. a. (1920) en J. M. Barrera: El Ultraismo... cit. t. I, p. 67. 
Raida y Luciano de San Saor (Lucía S. Saornil) ${ }^{14}$. Sólo Borges «tan estricto para el elogio» — según ha recordado Guillermo Mosquera- consideró su figura y ponderó su significación como «uno de aquellos escritores que, en torno a Grecia, iniciaban desde nuestra ciudad una línea de renovación de la prosa narrativa» ${ }^{15}$.

Tanto su biografía como su obra han quedado inéditas. ¿Quién fue este personaje, aparentemente «secundario» del Vltra? Luis Guillermo Mosquera Diácono nació en su domicilio de Sevilla, calle Rodrigo Caro 12, «el día 5 de mayo a las cuatro y cuarto de la noche» ${ }^{16}$. Sus padres fueron D. Luis Mosquera de Montes, funcionario municipal (empleado) y Dñ.a Guillermina Diácono y Cardur, ambos naturales de Sevilla. Sus abuelos paternos, D. Ricardo Mosquera y Dña Estela de Montes, eran de Cádiz y los maternos, D. José Diácono, malagueño y Dñ. Manuela Cardur, gaditana.

Como su padre - siguiendo una tradición familiar - fue Empleado Oficial de Intervención en el Ayuntamiento Sevillano y trabajó también en el despacho del abogado Rodríguez de la Borbolla. Se casó con Dñ. ${ }^{a}$ Filomena Alonso Ruiz, natural también de Sevilla, en 1914 y tuvo 4 hijos: Guillermo, Luis -ha fallecido-, José y Manuel. Desde su matrimonio residía en la calle Resolana 18, donde le sobrevino la muerte «a la edad de sesenta y cinco años a las 16 horas del día 18 de noviembre de $1955{ }^{17}{ }^{17}$, consecuencia de un 'ictus apoplético'. Ningún periódico se hizo eco de su fallecimiento, a excepción de El Correo de Andalucía, desde cuyas páginas Joaquín Romero glosaba su vida y obra. Allí mismo, el autor de Sombra apasionada (1929) trazaba un magnífico retrato de nuestro escritor: «El parecía tenerle miedo a la vida. Arrotraba los días, los hechos, las obligaciones ineludibles con una oblicuidad de gesto, como persona que se defiende al sesgo contra un vendaval que terminaría por derribarle. ¿presagio anticipado de su final doloroso? Pero cuando quedaban vencidas las defensas de su timidez, de su poquedad, social, de su figura huidiza, calva, morena y silenciosa, nos contagiaba con leve media sonrisa, una lumbre interior intensa y descompesada con las circunstancias y un fino resentimiento que no llegaba a cuajar ni en envidia ni en maldad, porque cristianamente él lo deslizaba por el cauce de la ironía o de la resignación apacible. Y huía de la calle, huía de la gente. Sólo su casa, los suyos, y su modestia llena de escogidas lecturas, y su vocación de escritor llena de desamparos.... ${ }^{18}$.

Su papel dentro de la vanguardia, en las revistas de los años veinte, fue muy importante. Su inicio literario tuvo lugar en la «Revista de Literatura» dirigida

14 Germán Gullón (ed.) Poesía de la Vanguardia Española. Ed. Taurus, col. Temas de España, 109, Madrid, 1981, p. 175 y p. 129.

15 Guillermo Mosquera Alonso: «Recuerdo sevillano de Jorge Luis Borges» El Correo de Andalucía. Suplem. Literario, 3 marzo de 1986, p. 19.

16 Acta de Certificación de Nacimientos. Fol. 128 del tomo 71 Sección 1a del Registro Civil de Sevilla (4).

17 Acta de Certificación de Defunción. Fol 36 vt.o, tomo 320, sección 3. del Registro Civil de Sevilla (3).

18 J. Romero Murube: Art. cit. 
por su amigo Isaac del Vando — de la misma edad y formación-, Grecia. Su modernismo externo, sensual y cosmopolita, con ribetes filosóficos, se observa a lo largo de los primeros «Cuentos Quincenales», publicados en 1918: «Aquella Eulalia» (n. 1. 12 octubre 1918, pp. 6-9), «Iniciación« (n. 2, 1 noviembre 1918, pp. 10-13), «Sofonisbe» (n. 4, 1 diciembre 1918, pp. 11-14) y «Las siegas de Gomorra» (n. 5, 15 diciembre 1918, pp. 7-9). El erotismo es, sin duda, el tema obsesivo y recurrente en todos ellos. Lo erótico, como su extremo lo místico, lleva a un mismo afán: la trascendencia, el anhelo de inmortalidad. Eulalia es el objeto del deseo sexual con final de ruptura, unos primos se hermanan pero las diferencias de edad dificultan el amor, amores lesbianos que se suceden en Gomorra con la castración de un joven efebo de Sodoma por las mujeres lascivas... etc; todos ocultan el verdadero motivo del escritor: la búsqueda de la belleza, el goce del cuerpo ante el Narcisismo. Esta preocupación es bien antigua en la literatura: los novelistas de folletín, de tratamiento erótico - dentro de la bohemia y la acracia fin de siglo- inciden en los jóvenes de los felices veinte ${ }^{19}$.

Durante 1919, tuvo lugar su «transfiguración», su conversión al altar del Ultra, al igual que el resto de sus compañeros. Con todo, Mosquera al igual que Adriano del Valle o Garfias no rompió definitavamente con su formación modernista. Mientras Grecia fue quincenal - hasta el n. 13, 15 abril 1919- siguió publicando sus «Cuentos Quincenales» («La lección», n. 6, 1 enero 1919, pp. 9-11, «El divino poder», n. 7, 15 enero 1919, pp. 12-13 y «Una noche del Yosiwara», n. 9, 15 febrero 1919, pp. 10-12), notas críticas («Adriano del Valle en el Ateneo» n. 10, 1 marzo 1919, pp. 14-15) y prosas poéticas («Los humildes» n. 10, 1 marzo 1919, pp. 7-9 y «Los domingos en la Plaza de América» n. 12, 1 abril 1919, pp. 9-10). Su primer poema incluido en la revista «Blanca Psiquis» (n. 3, 15 noviembre 1918, p. 12) denota la filiación al modernismo sensitivo, al «estilo mediterráneo» del que él mismo hablara a propósito de las raíces griegas y latinas de Adriano del Valle ${ }^{20}$. En serventesios dodecasílabos, los continuos símbolos (jardines, rosas, surtidores, luna...) son marcos referenciales de las almas sensitivas que ya presienten o quienes presentir el cambio estético, los «anhelos ingenuos y vagos» (v. 9). Con «Ensayo de Moderna Lírica» (n. 11, 15 marzo 1919, p. 11) intuye el cambio lírico a través de las imágenes noviformales: la tierra se abre «con raído temblor/ de batir de párpados» (vs. 3-4), los «árboles tienen grises capotes de miel» (v. 10), etc. Los distintos Ultraísmos comienzan a configurarse en su obra. Desde «Noche» —también «Ensayo de Moderna Lírica» (n. 13, 15 abril 1919, p. 13) con un Ultra de imágenes inconexas, sin caer en el dadaísmo, con el desarrollo del simil, hasta «Viaje Orbicular» (n. 35, 10 diciembre 1919, p. 6), caligrama perfecto, que representa un reloj de arena o clepsidra, con el Impasible Kronos y el Universo como centro, y «Avatar» (n. 36, 20 diciembre 1919, p. 11), donde el Ultra existencial y romántico alcanza su cumbre, no sin retroceder antes con «Interrogaciones» (n. 19, 20 junio 1919, p. 13) —-soneto de versos alejandrinos

19 J. M. Barrera: Op. cit. t. I, p. 55.

20 Luis Mosquera: «Adriano del Valle en el Ateneo» Grecia n. 10, 1 marzo 1919, p. 15, reprod. en José M. Barrera: Op. cit. T. I, p. 306. 
con fondo simbolista-, dan la totalidad de su producción, en la ya decenal y, en pequeña parte, madrileña revista.

Hermanada con Grecia, Vltra de Oviedo, dirigida por Augusto Guallart y con Joaquín de la Escosura, Luis Zubillaga y Gonzalo de Alvar como redactores, dio cabida a los integrantes del grupo de Sevilla (A. del Valle, Cansinos, M. Forcada y Mosquera). José Luis Roca ha señalado las relaciones de amistad de A. del Valle con Mosquera y Vando - Villar ${ }^{21}$. A nuestro autor le dedica Adriano, el poema «El sátiro a la satiresa» (n. 4, 15 diciembre 1919) y lo define «centáurida de las florestas del Arte». Por su parte, Mosquera le dedicó a Juan Las (Cansinos) «Las locomotoras doncellas (n. 3, 1 diciembre 1919, p. 20), en claro correlato a la prosa que éste publicó en ese mismo número, titulada «locomotoras». El erotismo vuelve a aparecer unido al futurismo más innovador. Toda la carga inventiva del objeto «Locomotora» queda convertido en «mujer»: «Unico seno/erecto» (chimenea), «Torso de hembra potente y joven» (perfil de la máquina) «vientre virginal» (caldera de la locomotora), etc. En una colaboración anterior de Vltra, «Crepúsculo de lluvia», n. 2, 15 noviembre 1919, p. 16), la ciudad de humaniza, en metagogia perfecta («Los faroles urbanos se desangran melancólicamente y sobre los espejos del asfalto») y la imagen queda en el ámbito de la greguería («Un hombre inmóvil espera / en cada extremo de la calle / que parece un renglón entre dos interrogaciones...»).

En la revista Gran Gvignol de Sevilla —dirigida por Manuel Calvo Ochoa, empleado también del Ayuntamiento hispalense- publicó un poema «Era blanca como una estrella» (n. 2, 10 marzo 1920), una narración de tema amoroso (incesto) titulada «A bordo» (n. 1, 10 febrero 1920) y la crítica del libro Monedas de Cobre del poeta canario Saulo Torón (n. 1, cit.). Reclama en este, la influencia del «Espíritu diáfano y emocional de Fracis Jammes» y recuerda a Pedro Salinas «que da la justa sensación de este buen libro». Salinas era por aquel tiempo catedrático de Literatura en la Universidad y observaba con distanciamiento el 'fenómeno' ultraísta (de hecho no colaboró nunca en ninguna publicación ultraica).

Aunque Mosquera es relegado de Vltra de Madrid, su nombre figura ampliamente en la «refundición» de Grecia, Tableros, editada igualmente en la capital por Isaac del Vando. Al mismo Mosquera se debe el Prólogo o Propósito de la revista, titulado «Tablero» (n. 1, 15 noviembre 1921, pp. 1-2). En los terrenos de la fábula didáctica, el tablero simboliza el espacio de la vida agitada moderna, donde continuas piezas del engranaje burgués son trasunto de las vidas humanas. El poeta se pregunta el motivo de tan «febril agitación», se recluye en su melancolía y mira hacia lo más alto «donde se halla el gran libro de estampas abierto, mostrando las historias de sus páginas incontables». Las prosas publicadas en esta época son muy distintas de las de Grecia. En «tres narraciones» (n. 2, 15 diciembre 1921 , p. 15), la sinestesia y la prosopopeya de la ciudad se unen a la metáfora insólita («Un farol encendido en una esquina es la única pupila despierta» «Las calles enarcan sus lomos grises y se desperezan satisfechas» Prosa II Los barrios extremos). La reflexión filosófica sobre las «Tres eternidades» (n. 3, 15

21 José Luis Roca: Art. cit. 
enero 1922, p. 11) y el humor absurdo de Ramón entre lo insólito y lo filosófico en «El coleccionista de horas» (n. 4, 28 Febrero 1922, p. 2) completan su aportación a la Revista Internacional de Arte, Literatura y Crítica «menos unilateral y expresiva que Vltra» a juicio de G. de Torre ${ }^{22}$.

Si en prosa y poesía fue conocedor de todos los recursos nuevos, también se planteó una decidida renovación del teatro. Muchas de sus obras han quedado inéditas, en poder de sus hijos, mientras otras fueron llevadas a la escena directamente y no se plasmaron en volumen.

El 16 de marzo de 1920, estrenó en el Teatro del Duque de Sevilla, Eterna Bohemia. Según la prensa de la época, estuvo representándose hasta el día 22 de marzo. En esas fechas, Uranophile (Miguel Romero y Martínez) desde su sección «Charivari» (El Liberal, n. 6.920, 18 marzo de 1920, p. 3) decía: «en la pirueta ultraica, formando parte del séquito del amable pontífice Vando-Villar, jugueteando en heteróclito y parlando en sintaxis cubista y para que nada falte (...)», quizá como una crítica encubierta de su posición teatral.

Tampoco fue un éxito su segunda obra —esta vez una zarzuela-, titulada Maricruz. La prensa sevillana deba la siguiente referencia: «Teatro del Duque. El viernes 2 de marzo de 1923, a las 10 y media. Estreno de la zarzuela en un acto, dividido en cuatro cuadros, original de Luis Mosquera, música del maestro Salvador. Maricruz «(El Liberal, n. 8.170, 2 de marzo de 1923, p. 3). La crítica la realizó A. R. (Antonio Rodríguez de León): «El asunto nada tiene de nuevo, y en general, la obra, si no alcanzó un éxito definitivo, tampoco fracasó. Fue una de tantas y nada más; de esas que ni enfrían ni calientan. La partitura tiene algunos números agradables, entre ellos el intermedio del segundo al tercer cuadro, que fue muy aplaudido y mereció los honores de la repetición. El barítono señor Lledó cantó muy bien la parte a él encomendado, haciéndose acreedor al justo aplauso del público, estando igualmente bien en sus respectivos papeles Enrique Morillo y Emiliano Latorre» (El Liberal, n. 8.171, 3 marzo de 1923, p. 4).

La obra de más calidad, sin duda es Rompecabezas, comedia escrita en 1920, en colaboración con Valdo-Villar, y publicada en Madrid, en 1921 — según figura en portada-, pero impresa en Sevilla, en «La Exposición». Con grabados de Barradas, separando los tres actos, va dedicada «A la Excelentísima señora Condesa de Lebrija». Este «libro de avanzada» según la nota de Vltra de Madrid (n. 17, 20 octubre 1921) fue criticado por Guillermo de Torre, desde las páginas del n. 1 de Tableros. El madrileño ve en la obra la dificultad de los 'poetas puros' forjados en otras latitudes selectas, que no se dejan seducir por los escenarios, el esfuerzo ímprobo del artista por rehusar «el manjar del público»: «Yo sólo he admirado un diagrama que describe la órbita del proceso sentimental experimentado por un corazón femenino de artista. Mujer seductora y parabólica, poseída de la manumisión mental, cuya brújula cardíaca fluctúa, digna de un pugnaz dualismo en el que vencen al fin sus puros instintos de mujer antes que artista». La protagonista de la comedia es una pintora, que expone en el Salón de arte Moderno, dentro de la vanguardia (¿quizá Norah Borges?), su estilo «decorado al gusto

22 G. de Torre: Op. cit., p. 53. 
exótico y lujoso de los grandes artistas de vanguardia en París» (acotación de la Es. 1. Acto 1., p. 9), dentro de una familia burguesa (D. Carlos, Dñ. Carmen), en un círculo intelectual progresista (Enrique, defensor de las vanguardias, dadaísmo) que renuncia a ser mujer, a enamorarse, por sentirse antes que nada, artista: «El artista es superior a su condición humana; yo puedo representar un valor, más puro mientras más me olvide de que soy una mujer como las otras mujeres. Me basta con interpretar la vida que desfila ante mí, con vivirla en espíritu, intensamente, sin tomar en ella parte material...» (Es. 2. , Acto II, p. 29). En este mundo del Arte, un tercer personaje, Jorge de Alenzano, que se denomina «materialista», le ofrecerá otra visión de su problemática: «¿Acaso el amor es incompatible con el Arte? (Es. 3a , Acto I, p. 12) y le regala un rompecabezas, símbolo de la mujer nueva: «era un símbolo de usted, pero al mismo tiempo es un símbolo de todos los seres humanos. Porque nosotros somos como piezas de un rompecabezas, revueltas e incoherente, donde hay trozos de un paisaje, y cuando llega una mano hábil que va ordenándolas, surgen, poco a poco, árboles, casitas de techos rojos y chimeneas humeantes, mozas que llevan la leña... De la misma forma, las manifestaciones desordenadas y confusas de nuestro temperamento van coordinándose por una influencia superior hasta que queda completamente revelado el verdadero carácter...» (Es. 5., Acto III, p. 53). Sin embargo, Nancy, la protagonista, rechaza que Jorge recomponga sus piezas: «mi paisaje interior, ese paisaje que ha pretendido usted descubrir, se encuentra formado ya por mis propias manos»(ibidem). La obra adquiere así la tesis de defensa de la emancipación de la mujer, de participación de la mujer por las «razones sociales» de las que hablará Díaz Fernández, años después en su libro El nuevo romanticismo ${ }^{23}$. Muy distinto es el amor de Jorge por Nancy de aquel otro de Pierrot y Arlequín por Colombina — tiranía de reina y señora - en el cuento «representable» «El divino poder» (cit.) publicado en Grecia.

En 1924, publicó dos novelas: Después de los dioses y Un pobre hombre. La primera no ha llegado apenas al lector, pues el mismo autor, debido a su acentuado erotismo, retiró la edición de las librerías. Fue financiada por José María del Campo, maestro y amigo del escritor. Joaquín Romero Murube esozó una pequeña crítica en su artículo de recuerdo: «Un libro de jugosa y correctísima prosa dannunziana, Después de los dioses, en el que el tropel indómito de las fuerzas vitales estaba tan lejos de esta triste fecha que hoy nos une en su recuerdo (...). Sobre su corrección formal y brillante, sobre su ingenuidad temática, olvidando la morosidad de mal gusto en determinadas escenas escatológicas, qué Sevilla más real y huída aquella del año 1925, con las huelgas, atentados sociales, cabaret de Eritaña y plaza de toros Monumental en San Bernardo. La novela desplaza su valor literario hacia un campo de levísimo, gráfica, directa información de la vida de la ciudad. Y todo expresado con prosa de una concreción dura, perfecta y luminosa. Y todo revestido también ya de una vejez casi arqueológica».

Un extracto de esta novela se publicó en la colección La Novela de día. Publicación semanal, en su número 15, correspondiente a enero de 1924, en los Ta-

23 J. Díaz Fernández: El nuevo romanticismo. Polémica de arte, política y literatura. Ed. Zeus, 1930, reed. facs. José Esteban, editor, Madrid, 1985, p. 38. 
lleres tipográficos de L. Izquierdo, de Sevilla, bajo el título Un pobre hombre. Francisco Coves, en «Un pobre hombre» (a modo de prólogo) «habla de la trilogía que todo escritor lleva dentro: «Con amargura contemplados frente a nosotros dos - esos dos, el hombre y el poeta, que somos uno mismo- a un tercer fantasma de nuestro mismo ser: el pobre hombre. Somos tres en uno solo: el Poeta, Hombre-Dios que de la nada fabrica mundos a su antojo a fuerza de gestosinvisibles; el hombre, sencillamente, y el pobre hombre, encorvado, con el mundo casero encima, andando sin ganas, con el alma a rastras».

La novela, en su apariencia sentimental, con connotaciones filosóficas, quiere mostrar algo más siempre y concluye con un problema de identidad. Un caso aparente y claro de adulterio por parte de la mujer del protagonista queda resuelto con una gran crisis de personalidad, de valores que sobrepasan la esfera individual y justifican una nueva mora social (¿justificación a posteriori de las vanguardias?). Se da crédito al engaño amoroso por la ética nietszcheana, por la moral de los vencedores: «es que yo no podía vivir tu vida, sometida, mediocre, adaptada a los términos medios. Me entregué a ese hombre como me hubiera entregado a otro cualquiera, como una cosa como un objeto sin dueño, que pasa de mano en mano sin pertenecer a nadie. Sólo los triunfadores, los que no se conforman con quedarse en la falda de la montaña, los que llegan hasta la libertad de la cumbre, pueden conservar lo que es suyo» (pp. 25-26). Interesante es observar la dualidad del protagonista, Enrique, que es optimista, vital, símbolo del trabajo - a su vez el esclavo y el engañado- y su hermano, Andrés, que representa la bohemia, el dolor, la inferioridad, pero libre y descubridor del engaño. Este dualismo conlleva una teoría doble sobre el dolor — manifestación schopenhariana-: el dolor que purifica la vida y, por tanto, es provechoso, es la vida misma (Andres) y el dolor como accidente, frente a lo importante que es la vida «que sale siempre purificada y triunfante» (Enrique). Sin duda, por boca de Andrés se enuncia el tema de la primera novela: "Afirman las personas — decía- que después de los dioses son los hombres los seres más perfectos de la creación, pero esto es falso, absolutamente falso». La consecuencia de esa imperfección es la avidez insaciable, el martirio que durará siempre en la mujer de Enrique, Concha. por eso, cuando el optimista, el infeliz, comprende que es engañado por su mujer tiene conciencia de esa imperfección: «llegó un segundo en que no experimentó ningún sentimiento de humillación, ni de odio, ni de pesadumbre. Era completamente ajeno a su tragedia. Su espíritu, por instinto de conservación, trataba de alejarse, de huir hacia la serenidad de las cosas abstractas, en los que se puede ser espectador de todas las miserias sin sentir el dolor de la llaga propia, donde se empequeñecen infinitamente los dramas subjetivos, perdidos en la inmensa armonía del mundo» (p. 24).

En junio de 1926, comienza a publicarse en Sevilla la revista Mediodía. Muchos ex-ultraístas se adhieren a ella, aunque no en cargos de dirección. Miguel Romero Martínez es citado como «impulsor» del nuevo grupo ${ }^{24}$, Adolfo Carre-

24 Joaquín Romero Murube: Poesías de Alejandro Collantes de Terán, precedidas por el homenaje literario de varios amigos del autor, Sevilla, 1949, p. 15, citado por Francisco López Estrada: «Biografía de Miguel Romero» en Homenaje a M. Romero Martínez (Sevilla, 1973) p. 47. 
tero, Adriano del Valle, Rogelio Buendía colaboran en sus números... ${ }^{25}$, el libro clave para entender el paso del Ultra a la Poesía Pura, El Ala del Sur de Garfias es analizado por Romero Murube ${ }^{26}$. En este ambiente tan propicio, Luis Mosquera publica una prosa ensayística y un breve cuento.

«La humilde irresolución de los inactuales» (n. 1, junio de 1926, pp. 11-12) es casi una declaración autobiográfica, al defender el 'ser inactual', fruto de pertenecer, no a una sino a todas las épocas. Nuestro autor resume el estar fuera de la 'actualidad estridente' («es grande el esfuerzo que hay que realizar para ser admitido llanamente, sin extrañeza, entre las cotidianas costumbres, entre los usos habituales; para conocer el léxico renovado, para adoptar los gustos nuevos, para iniciarse en las últimas orientaciones»), el aceptar la crítica («Tú ya has pasado y no puedes amoldarte a esta época, que no es la tuya»), para apostar definitivamente por la 'vida repetida y sabia' («el regreso al apartamiento ideal tiene melancolía de crepúsculo»), resignado al fracaso: «En el pobre ser inactual va desapareciendo la sombra de su egotismo y se hunde en unos finos embozos de silencio».

«Los pájaros sabios» (n. 9, enero 1928, pp. 8-9) es un delicioso cuento en tres tiempos, mujer-soldado-estudiante. El horoscopo de los «pájaros sabios», de los gorriones que lo adivina todo» en la Sevilla de 1898, con «los oscilantes entusiasmos de la Marcha de Cádiz y patriotas coplas de comparsa en La Campana» ilumina una nueva lectura del Mundo de las Ideas, el fracaso como la justificación de la vida intelectual: «Pasas con el cargamento, siempre nuevo, recogiendo sonrisas escepticas, porque a las ideas sólo se les acepta su novedad cuando son de respetable vejez. Pero no ha de faltarle alguno que, por pasatiempo, falsifique tu mercancía con fingidos dulces de colorines y yemas de vidrio pintado. Este tendrá más éxito, tú te moriras de hambre».

Durante la guerra civil, sólo abandonó su velado ostracismo, para publicar un artículo sobre la Virgen María en El Correo de Andalucía, en 1936, a petición del Delegado de Cultura del Ayuntamiento. Su republicanismo — sobre todo, su admiración por Azaña- fue decantándose tras la nueva situación política que imposibilitó otra estética que no fuera la religiosa e intimista.

En la posguerra, en el diario España de Tanger, publicó varias poesías con el título de Camafeos. Con igual título, y bajo los auspicios de la clásica figurilla de Grosso de la Minerva de Grecia, en la Imprenta Bergalí J. O., de Sevilla, en 1949 según Romero Murube ${ }^{27}$, editó Tres Cuadernos de Prosas y Poemas. Sirva como ejemplo el Tercer Cuaderno (s.a.), donde una de las prosas titulada «Preferencias» cita un verso de Lorca («Buscar la voz de una gota en agua») y supone una fuerte crítica el creacionismo («resulta un tanto afónico ese hallalí catarroso de petulancia. Los gestos mínimos describen una raya de sombra en la franja de luz de que están los muros revestidos, pero se suceden constantemente y surge

25 A. Carretero: «Orquestaciones. Oh, la tristeza de esta plaza» n. 1, junio 1926.; A. del Valle «Interpretación de Debussy» n. 2, julio 1926, «San Crisóbal» n. 11, marzo 1928; R. Buendía «Poemas de la vida en el Puerto»n. 3, agosto, 1926.

26 J. R. M. «El Ala del Sur. Poemas de P. Garfias», Mediodía, n. 1, junio 1926.

27 J. Romero: Art. cit. 
de ellos el movimiento que es la belleza»). Unos «Apuntes — poesías- al final del volumen denotan la influencia del «maestro» Antonio Machado, en la línea del 'autofolklore' que tanto criticó Cansinos ${ }^{28}$. Por lo demás, en las narraciones principales, tales como «Tibi soli pecavi», «La viuda» o «La selva» se observa una depuración del erotismo y decadentismo de las ofrecidas en Grecia, casi treinta años antes.

Poco más puede conocerse de este «raro» escritor. Acaso sólo nos quedaría suscribir las certeras palabras de Romero Murube en el único recordatorio de su muerte: «Preguntaríamos a la mayoría de los jóvenes en la actual literatura y periodismo sevillanos quién era Luis Mosquera y poco sabrían contestarnos. Y el ha estado entre nosotros hasta hace pocos días. Su muerte, como su vida, ha sido silenciosa y huidiza».

28 R. Cansinos-Assens: La Nueva Literatura. T. III. La evolución de la Poesía. Madrid, Páez, 1927, p. 243. 
